\title{
Intervenção educativa em primeiros socorros para escolares da educação básica
}

Educational intervention in first aid for basic education students

Intervención educativa en primeros auxilios para estudiantes de educación básica

\section{Monalise Mara Rocha Santana ${ }^{\mathrm{I}}$, Luana Vieira Toledo ${ }^{\mathrm{II}}$, Tiago Ricardo Moreira ${ }^{\mathrm{III}}$, Katiusse Rezende Alves ${ }^{\mathrm{IV}}$, Luciane Ribeirov ${ }^{\mathrm{v}}$, Flávia Batista Barbosa de Sá Diaz ${ }^{\mathrm{VI}}$}

\begin{abstract}
Resumo: Objetivo: comparar o conhecimento de escolares do ensino básico sobre primeiros socorros antes e após uma intervenção educativa sobre o tema. Método: estudo quase experimental, realizado com 67 estudantes do oitavo ano do ensino fundamental de uma escola pública, durante o ano de 2015, em um município de Minas Gerais. Foram aplicados instrumentos de pré e pós-testes para a coleta de dados que, posteriormente, foram compilados no software Epi Info ${ }^{\mathrm{TM}}$ versão 7 e analisados pelo programa Statistical Package for the Social Sciences (SPSS) versão 20. Resultados: houve melhoria estatisticamente significativa $(\mathrm{P}<0,05)$ no conhecimento dos participantes após a intervenção educativa para a maioria dos temas abordados. Conclusão: a intervenção educativa em primeiros socorros para escolares foi efetiva e demonstrou a emergente necessidade de implementar disciplinas que abordem estes conteúdos no currículo do ensino básico.
\end{abstract}

Descritores: Enfermagem; Emergências; Primeiros socorros; Educação em saúde; Estudantes

Abstract: Objective: to compare the knowledge of basic education students about first aid before and after an educational intervention on the subject. Method: quasi-experimental study, conducted with 67 eighth-grade students of a public school, during 2015, in a city of Minas Gerais. Pre- and post-test instruments were applied for data collection, which were later compiled in Epi $\mathrm{Info}^{\mathrm{TM}}$ software version 7 and analyzed by Statistical Package for the Social Sciences (SPSS) version 20. Results: there was a statistically significant improvement $(\mathrm{P}<0.05)$ in the participants' knowledge after the educational intervention for most of the topics addressed. Conclusion: the

\footnotetext{
I Acadêmica de Medicina. Enfermeira. Centro Universitário Unifaminas Muriaé, Muriaé, Minas Gerais, Brasil. E-mail: monalisemrsantana@gmail.com ORCID: http://orcid.org/0000-0001-5380-5716

II Enfermeira. Doutora em Enfermagem. Universidade Federal de Viçosa, Viçosa, Minas Gerais, Brasil. Email: luana.toledo@ufv.br ORCID: http://orcid.org/0000-0001-9527-7325

III Enfermeiro. Doutor em Saúde Pública. Universidade Federal de Viçosa, Viçosa, Minas Gerais, Brasil. E-mail: tiago.ricardo@ufv.br ORCID: http://orcid.org/0000-0002-6606-4942

IV Enfermeira. Mestre em Enfermagem. Universidade Federal de Viçosa, Viçosa, Minas Gerais, Brasil. E-mail: katiusserezende@gmail.com ORCID: http://orcid.org/0000-0003-3393-8567

v Enfermeira. Doutora em Saúde Coletiva. Universidade Federal de Juiz de Fora, Juiz de Fora, Minas Gerais, Brasil. E-mail: luribeiro.jf@gmail.com ORCID: http://orcid.org/0000-0001-7856-5659

VI Enfermeira. Mestre em Saúde Coletiva. Universidade Federal de Viçosa, Viçosa, Minas Gerais, Brasil. E-mail: flaviabatis@yahoo.com.br ORCID: http://orcid.org/0000-0003-2360-3026
} 
educational intervention in first aid for schoolchildren was effective and demonstrated the emerging need to implement subjects that address these contents in the basic education curriculum.

Descriptors: Nursing; Emergencies; First aid; Health education; Students

Resumen: Objetivo: comparar los conocimientos de los estudiantes de la educación básica sobre primeros auxilios antes y después de una intervención educativa sobre el tema. Método: estudio casi experimental, realizado con 67 estudiantes del octavo grado de una escuela pública, durante 2015, en un municipio de Minas Gerais. Se aplicaron instrumentos de prueba previa y posterior para la recopilación de datos, que posteriormente se compilaron en la versión 7 del software Epi Info ${ }^{\mathrm{TM}}$ y se analizaron en el Statistical Package for the Social Sciences (SPSS) versión 20. Resultados: hubo una mejora estadísticamente significativa $(\mathrm{P}<0.05)$ en el conocimiento de los participantes después de la intervención educativa para la mayoría de los temas abordados. Conclusión: la intervención educativa en primeros auxilios para los escolares fue eficaz y demostró la necesidad emergente de implementar disciplinas que aborden estos contenidos en el currículo de educación básica.

Descriptores: Enfermería; Urgencias médicas; Primeros auxilios; Educación en salud; Estudiantes

\section{Introdução}

A urgência se define como uma ocorrência imprevista de danos à saúde em que não há risco de morte, enquanto que a emergência implica risco iminente de morte. ${ }^{1}$ Em situações de urgência e emergência a avaliação da vítima e seu atendimento devem ser eficazes, permitindo a redução de sequelas e o aumento da sobrevida. ${ }^{2}$

Os primeiros socorros (PS) constituem atendimento imediato que deve ser prestado com agilidade a uma pessoa, vítima de acidente ou de mal súbito, cujo estado físico põe em perigo a sua vida, de modo que àquele seja realizado previamente à assistência a ser prestada por um profissional de saúde. Seu objetivo é manter as funções vitais e evitar o agravamento das condições da vítima, utilizando medidas e procedimentos, na maioria das vezes simples, como avaliar o local onde a vítima se encontra, o seu estado físico, solicitar ajuda, até a chegada de assistência qualificada. Eles podem ser prestados por qualquer pessoa desde que treinada, devendo sempre ser conduzido com serenidade, compreensão e confiança. . $^{3-5}$

Mesmo com sua relevância e tendo em vista que os agravos à saúde acontecem em grande escala, cotidianamente, no trânsito, nos domicílios, no ambiente de trabalho e em outros locais, no Brasil, observa-se que a educação no contexto dos PS é pouco difundida, prevalecendo o 
desconhecimento sobre o tema. ${ }^{5}$ A prática educativa em saúde é uma estratégia do poder público para garantir o desenvolvimento de ações de controle e prevenção de doenças ou agravos, junto aos setores marginalizados da população. ${ }^{6}$ Nota-se que o ensino sobre PS deveria ser disponibilizado e democratizado para todos, porém, atualmente, aprender sobre o tema trata-se de um privilégio para poucos grupos. ${ }^{5}$ É indispensável que o acesso a estes conhecimentos seja democratizado e disseminado para toda sociedade, permitindo aos usuários cuidar melhor de sua saúde e tornarem-se menos vulneráveis.

A educação básica (EB) é referida como a base para a aprendizagem e o desenvolvimento humano permanentes, uma vez que seu espaço por excelência é o ensino. A instituição escolar representa atualmente o principal meio para promover a EB fora da esfera familiar e constitui o espaço em que as crianças e adolescentes passam cerca de um terço de seu tempo, tornando-se, dessa maneira, um ambiente favorável à ocorrência de situações de urgência e emergência. ${ }^{5,7}$ Destarte, a escola pode ser considerada o espaço ideal para o aprendizado em PS, visto que a mesma é o local em que há a difusão do saber. O que faz com que crianças e adolescentes desenvolvam entusiástica e despretensiosamente a capacidade e a facilidade de aprender e ensinar o conteúdo adquirido às outras pessoas, sejam familiares, amigos ou a própria comunidade onde se encontra inserida. ${ }^{8}$

Em países como os Estados Unidos, o ensino em PS já faz parte da educação básica, e na Noruega, o Suporte Básico de Vida (SBV) é ministrado às crianças em idade escolar desde a década de sessenta. ${ }^{9-10}$ Acredita-se que uma sociedade capacitada e bem treinada desde a EB se torna preparada para agir com rapidez e desenvoltura em situações em que há o comprometimento da vida, evitando ou minimizando possíveis desfechos trágicos. Vale lembrar que situações de urgência e emergência podem ocorrer em qualquer local e os PS podem ser prestados por qualquer pessoa. 
Considerando os aspectos citados, questiona-se: como é o conhecimento de escolares do ensino básico de uma escola pública sobre PS antes e após uma intervenção educativa sobre o tema? Diante do exposto, este trabalho teve como objetivo comparar o conhecimento de escolares do ensino básico sobre PS antes e após uma intervenção educativa sobre o tema.

\section{Método}

Trata-se de um estudo quase experimental, de caráter intervencionista, do tipo antes e depois, cuja intervenção empregada foram capacitações em primeiros socorros realizadas com estudantes do ensino básico, de uma escola pública de Minas Gerais nos meses de setembro a dezembro de 2015 .

Foram incluídos no estudo todos os estudantes regularmente matriculados no oitavo ano do ensino fundamental da referida escola $(n=67)$. Foram excluídos àqueles que não participaram de todas as atividades educativas realizadas e/ou que não preencheram adequadamente os instrumentos da coleta de dados $(\mathrm{n}=08)$.

A atividade educativa foi realizada seguindo as etapas: apresentação da proposta de capacitação para a direção da escola que a analisou, aprovou e indicou uma turma para a aplicação da ação. Foi pactuado entre os pesquisadores e a direção escolar que os temas abordados nas capacitações (PS) seriam parte integrante do conteúdo trabalhado na cátedra de ciências naturais para o ensino fundamental.

Teve-se como meta principal, através da reunião escolar realizada com os pais ou responsáveis pelos estudantes e a diretora da escola, apresentar os objetivos da pesquisa e informar os benefícios que as capacitações trariam para os estudantes, seus familiares e a comunidade como um todo. Vale ressaltar que todos os estudantes incluídos neste estudo aceitaram participar voluntariamente da pesquisa após convite realizado em sala de aula pelos autores, onde houve a explicação dos temas que seriam abordados e sua aplicação prática. 
Foram também apresentados os riscos mínimos que estariam envolvidos no projeto e quais os documentos exigidos para efetivar a sua participação.

As qualificações foram desenvolvidas utilizando-se metodologia dinâmica, com abordagem teórico-prática em 15 encontros, e com um tempo médio de 60 minutos de duração. Todos os encontros foram realizados em sala de aula e o intervalo entre cada habilitação foi de uma semana. Os temas abordados nas instruções foram: parada cardiorrespiratória (PCR), ressuscitação cardiopulmonar (RCP), crise convulsiva, hemorragia, epistaxe, fratura, luxação e entorse.

$\mathrm{Na}$ abordagem prática dos temas ministrados, utilizou-se a simulação realística para ensinar aos participantes as medidas que poderiam ser adotadas para a identificação, controle, cuidado e prevenção das situações trabalhadas. Para isso, foram utilizados materiais improvisados, tais como: sacola plástica, panos, mochilas, livros, revistas, cabos de vassoura e papelão, visto que, em casos em que não há os materiais próprios e específicos, todas as intervenções pertinentes a determinadas situações podem ser realizadas com qualidade.

A coleta de dados foi realizada por meio da aplicação de um instrumento de pré e pósteste desenvolvidos pelos pesquisadores do estudo, sendo a avaliação pós-teste realizada ao final de cada capacitação. O instrumento aplicado era do tipo autoavaliativo, ou seja, os participantes por julgamento próprio, informavam terem ou não conhecimento sobre os temas abordados antes e depois da intervenção educativa.

Os dados foram compilados no software Epi Info ${ }^{\mathrm{TM}}$ versão 7 e analisados pelo programa Statistical Package for the Social Sciences (SPSS) versão 20 para Windows. Para comparar o conhecimento antes e após a atividade, foi aplicado o teste de $M c N e m a r$, considerando nível de significância de $0,05 \%$. O teste de $M c N e m a r$ é um teste estatístico não paramétrico utilizado para comparar mudanças no pré e pós-teste de variáveis dicotômicas (sim ou não). ${ }^{11}$

Este estudo é parte integrante de uma pesquisa maior e respeitou os preceitos éticos e legais da Resolução no 466/12 do Conselho Nacional de Saúde, sendo conduzido após aprovação 
pelo Comitê de Ética em Pesquisa com Seres Humanos da Universidade Federal de Viçosa, que emitiu parecer favorável em 13/11/2014, sob o protocolo de número 870.833. Todas as atividades foram realizadas mediante a apresentação e aprovação da proposta para os pais ou responsáveis pelos estudantes, posteriormente a uma reunião escolar com a presença da diretora da escola e, em seguida a assinatura do Termo de Consentimento Livre e Esclarecido e do Termo de Assentimento.

\section{Resultados}

Dos 75 estudantes regularmente matriculados no oitavo ano da escola pública, participaram da pesquisa $67(89,3 \%)$, entre 12 a 17 anos de idade e em sua maioria do sexo masculino 35 (52,2\%). Com relação ao conhecimento prévio dos participantes sobre noções básicas em PS, observou-se desconhecimento total do assunto em 35 (52,2\%), ausência de formação ou atividade relacionada ao tópico em $66(98,5 \%)$ e tema considerado importante em 64 (95,5\%).

Notou-se que o conhecimento dos participantes sobre o tema PCR e RCP no pré-teste eram deficientes, contudo, após a intervenção educativa, os resultados do pós-teste foram melhores, observando-se uma diferença estatisticamente significativa $(P<0,05)$ para quase todas as variáveis analisadas. Apenas a variável referente ao conhecimento do número do serviço médico de emergência utilizado na cidade não apresentou diferença estatisticamente significante (Tabela 1). Portanto, a intervenção educativa foi considerada eficaz.

Tabela 1 - Distribuição das variáveis analisadas referentes ao conhecimento dos participantes sobre o tema Parada cardiorrespiratória (PCR/RCP) no pré e pós-teste. Viçosa, MG, Brasil, 2015

\begin{tabular}{lrrrrr}
\hline & \multicolumn{2}{c}{ Pré-teste } & \multicolumn{2}{c}{ Pós-teste } & Valor \\
\multicolumn{1}{c}{ Variáveis } & Sim & Não & Sim & Não & de $\boldsymbol{p}$ \\
& $\mathrm{n}(\%)$ & $\mathrm{n}(\%)$ & $\mathrm{n}(\%)$ & $\mathrm{n}(\%)$ & \\
\hline Sabe o que é uma parada cardiorrespiratória? & $34(50,7)$ & $33(49,3)$ & $53(78,8)$ & $14(21,2)$ & $0,001^{*}$ \\
Sabe o que acontece com uma pessoa que tem & $22(32,8)$ & $45(67,2)$ & $48(71,2)$ & $19(28,8)$ & $<0,001^{*}$ \\
uma parada cardiorrespiratória? & & & & & \\
Sabe identificar uma parada cardiorrespiratória? & $11(16,4)$ & $56(83,6)$ & $40(60,6)$ & $27(39,4)$ & $<0,001^{*}$ \\
Após identificar uma parada cardiorrespiratória, & $8(11,9)$ & $59(88,1)$ & $36(53,0)$ & $31(47,0)$ & $<0,001^{*}$ \\
\hline
\end{tabular}




\begin{tabular}{lrrrrl}
\hline $\begin{array}{l}\text { sabe exatamente o que fazer? } \\
\text { Sabe prestar os primeiros socorros a uma pessoa }\end{array}$ & $7(10,4)$ & $60(89,6)$ & $36(53,0)$ & $31(47,0)$ & $<0,001^{*}$ \\
$\begin{array}{l}\text { com cardiorres piratória? } \\
\text { Sabe fazer massagem cardíaca? }\end{array}$ & $18(26,9)$ & $49(73,1)$ & $42(63,6)$ & $25(36,4)<0,001^{*}$ \\
$\begin{array}{l}\text { Sabe quantas massagens cardíacas deve fazer por } \\
\text { minuto? }\end{array}$ & $6(9,0)$ & $61(91,0)$ & $30(45,5)$ & $37(54,5)<0,001^{*}$ \\
$\begin{array}{l}\text { Sabe o número do serviço médico de emergência } \\
\text { utilizado na cidade? }\end{array}$ & $34(50,7)$ & $33(49,3)$ & $44(66,7)$ & $23(33,3)$ & $0,089^{*}$
\end{tabular}

Fonte: Elaborada pelos autores com base na coleta de dados da pesquisa, 2015.

* Teste de McNemar

Também foi encontrado uma melhoria estatisticamente significativa $(P<0,05)$ no conhecimento dos participantes sobre os temas hemorragia/epistaxe e crise convulsiva após a intervenção educativa (Tabela 2).

Tabela 2 - Distribuição das variáveis analisadas referentes ao conhecimento dos participantes sobre os temas hemorragia/epistaxe e crise convulsiva no pré e pós-teste. Viçosa, MG, Brasil, 2015

\begin{tabular}{|c|c|c|c|c|c|}
\hline \multirow[b]{2}{*}{ Variáveis } & \multicolumn{2}{|c|}{ Pré-teste } & \multicolumn{2}{|c|}{ Pós-teste } & \multirow{2}{*}{$\begin{array}{l}\text { Valor } \\
\text { de } p\end{array}$} \\
\hline & $\begin{array}{c}\operatorname{Sim} \\
\mathrm{n}(\%)\end{array}$ & $\begin{array}{l}\text { Não } \\
n(\%)\end{array}$ & $\begin{array}{c}\operatorname{Sim} \\
\mathrm{n}(\%)\end{array}$ & $\begin{array}{l}\text { Não } \\
n(\%)\end{array}$ & \\
\hline \multicolumn{6}{|l|}{ Hemorragia/Epistaxe } \\
\hline Sabe identificar uma hemorragia? & $17(25,4)$ & $50(74,6)$ & $48(71,2)$ & $19(28,8)$ & $<0,001^{*}$ \\
\hline Conhece os diferentes tipos de hemorragia? & $9(13,4)$ & $58(86,6)$ & $36(53,0)$ & $31(47,0)$ & $<0,001^{*}$ \\
\hline Após identificar uma hemorragia, sabe o que fazer? & $12(17,9)$ & $55(82,1)$ & $42(63,6)$ & $25(36,4)$ & $<0,001^{*}$ \\
\hline $\begin{array}{l}\text { Sabe o que fazer diante de um sangramento nasal } \\
\text { (epistaxe)? }\end{array}$ & $14(20,9)$ & $53(79,1)$ & $37(56,1)$ & $30(43,9)$ & $<0,001^{*}$ \\
\hline Sabe como controlar um sangramento? & $29(43,3)$ & $38(56,7)$ & $51(75,8)$ & $16(24,2)$ & $<0,001^{*}$ \\
\hline Sabe o que é um torniquete? & $8(11,9)$ & $59(88,1)$ & $40(59,1)$ & $27(40,9)$ & $<0,001^{*}$ \\
\hline Sabe fazer um torniquete? & $8(11,9)$ & $59(88,1)$ & $33(50,0)$ & $34(50,0)$ & $<0,001^{*}$ \\
\hline Sabe em qual situação o torniquete pode ser usado? & $5(7,5)$ & $62(92,5)$ & $34(50,0)$ & $33(50,0)$ & $<0,001^{*}$ \\
\hline $\begin{array}{l}\text { Sabe quais cuidados devem ser tomados ao } \\
\text { tentar controlar (estancar) um sangramento? }\end{array}$ & $22(32,8)$ & $45(67,2)$ & $48(71,2)$ & $19(28,8)$ & $<0,001^{*}$ \\
\hline \multicolumn{6}{|l|}{ Crise Convulsiva } \\
\hline Sabe identificar uma crise convulsiva? & $22(32,8)$ & $45(67,2)$ & $52(77,3)$ & $15(22,7)$ & $<0,001^{*}$ \\
\hline $\begin{array}{l}\text { Sabe o tempo médio de duração de uma crise } \\
\text { convulsiva? }\end{array}$ & $5(7,5)$ & $62(92,5)$ & $42(62,1)$ & $25(37,9)$ & $<0,001^{*}$ \\
\hline $\begin{array}{l}\text { Após identificar uma crise convulsiva, sabe o que } \\
\text { deve fazer? }\end{array}$ & $5(7,5)$ & $62(92,5)$ & $43(63,6)$ & $24(36,4)$ & $<0,001^{*}$ \\
\hline $\begin{array}{l}\text { Sabe que medida você deve tomar quando a crise } \\
\text { convulsiva acabar? }\end{array}$ & $7(10,4)$ & $60(89,6)$ & $40(60,6)$ & $27(39,4)$ & $<0,001^{*}$ \\
\hline
\end{tabular}

Fonte: Elaborada pelos autores com base na coleta de dados da pesquisa, 2015.

* Teste de McNemar 
Sobre os temas fratura, luxação e entorse também houve uma melhoria estatisticamente significativa $(\mathrm{p}<0,05)$ no conhecimento dos participantes após a intervenção. Entretanto, algumas variáveis analisadas (“Sabe o que é fratura?” e "Sabe identificar uma fratura?”), não apresentaram melhorias estatisticamente significativas $(\mathrm{p}>0,05)$, dado que a temática já possuía um percentual de conhecimento prévio mais alto que as demais temáticas abordadas (Tabela 3).

Tabela 3 - Distribuição das variáveis analisadas referentes ao conhecimento dos participantes sobre os temas fratura, luxação e entorse no pré e pós-teste. Viçosa, MG, Brasil, 2015

\begin{tabular}{|c|c|c|c|c|c|}
\hline \multirow[b]{2}{*}{ Variáveis } & \multicolumn{2}{|c|}{ Pré-teste } & \multicolumn{2}{|c|}{ Pós-teste } & \multirow{2}{*}{$\begin{array}{l}\text { Valor } \\
\text { de } p\end{array}$} \\
\hline & $\begin{array}{l}\operatorname{Sim} \\
n(\%)\end{array}$ & $\begin{array}{c}\text { Não } \\
\text { n(\%) }\end{array}$ & $\begin{array}{l}\operatorname{Sim} \\
\mathrm{n}(\%)\end{array}$ & $\begin{array}{l}\text { Não } \\
\mathrm{n}(\%)\end{array}$ & \\
\hline \multicolumn{6}{|l|}{ Fratura } \\
\hline Sabe o que é fratura? & $46(68,7)$ & $21(31,3)$ & $52(77,3)$ & $15(22,7)$ & $0,189^{*}$ \\
\hline Sabe identificar uma fratura? & $39(58,2)$ & $28(41,8)$ & $48(71,2)$ & $19(28,8)$ & $0,093^{*}$ \\
\hline $\begin{array}{l}\text { Sabe o que fazer após identificar } \\
\text { uma fratura? }\end{array}$ & $12(17,9)$ & $55(82,1)$ & $41(62,1)$ & $26(37,9)$ & $<0,001^{*}$ \\
\hline \multicolumn{6}{|l|}{ Sabe como imobilizar } \\
\hline \multicolumn{5}{|l|}{ Luxação } & $<0,001^{*}$ \\
\hline Sabe o que é luxação? & $6(9,0)$ & $61(91,0)$ & $42(62,1)$ & $25(37,9)$ & $<0,001^{*}$ \\
\hline Sabe identificar uma luxação? & $4(6,0)$ & $63(94,0)$ & $35(53,0)$ & $32(47,0)$ & $<0,001^{*}$ \\
\hline $\begin{array}{l}\text { Sabe o que fazer após identificar } \\
\text { uma luxação? }\end{array}$ & $5(7,5)$ & $62(92,5)$ & $33(48,5)$ & $34(51,5)$ & $<0,001^{*}$ \\
\hline $\begin{array}{l}\text { Sabe como imobilizar } \\
\text { adequadamente o membro afetado? }\end{array}$ & $6(9,0)$ & $61(91,0)$ & $33(50,0)$ & $34(50,0)$ & $<0,001^{*}$ \\
\hline \multicolumn{6}{|l|}{ Entorse } \\
\hline Sabe o que é entorse? & $5(7,5)$ & $62(92,5)$ & $34(50,0)$ & $33(50,0)$ & $<0,001^{*}$ \\
\hline Sabe identificar uma entorse? & $4(6,0)$ & $63(94,0)$ & $31(45,5)$ & $36(54,5)$ & $<0,001^{*}$ \\
\hline Sabe o que fazer após identificar & & & & & \\
\hline uma entorse? & $1(1,5)$ & $66(98,5)$ & $29(43,9)$ & $38(56,1)$ & $<0,001^{*}$ \\
\hline Sabe como imobilizar & & & & & \\
\hline adequadamente o membro afetado? & $5(7,5)$ & $62(92,5)$ & $27(40,9)$ & $40(59,1)$ & $<0,001^{*}$ \\
\hline
\end{tabular}

\section{Discussão}

A presente investigação evidenciou que a maioria dos estudantes nunca realizou algum curso ou capacitação em PS e que possuíam pouco ou nenhum conhecimento sobre o tema, o 
que corrobora com os achados de outra pesquisa, cujo objetivo foi investigar a necessidade da inclusão da disciplina de PS na EB a partir das produções científicas. ${ }^{12}$ Sabe-se que os acidentes podem ocorrer em qualquer ambiente e os estudantes precisam ter conhecimento e saber como agir frente a esses eventos. Além disso, mais de 50\% dos casos de acidentes são presenciados por adolescentes ou crianças, sem um adulto por perto, sendo necessária a imediata intervenção de profissionais com conhecimento na área de primeiros socorros. ${ }^{12}$

Da mesma forma, outro estudo desenvolvido no município de Cuité, no Curimataú Paraibano, com estudantes de 13 a 15 anos, também demonstrou que o nível de conhecimento em PS foi considerado insatisfatório para permiti-los atuar em situações de urgência e emergência, justificando a necessidade de instituir essa disciplina na grade curricular de todas as escolas. ${ }^{13}$ Tal assertiva é fortemente reforçada pela implementação da declaração conjunta “Kids Save Lives” (KSL), desenvolvida pelo “European Resuscitation Council” (ERC), “European Patient Safety Foundation" (EPSF), “International Liaison Committee on Resuscitation" (ILCOR), “World Federation of Societies of Anaesthesiologists” (WFSA), e posteriormente, apoiada pela “World Health Organization” (WHO) em janeiro de 2015. Essa declaração constitui uma tentativa para a implantação de cursos de formação em primeiros socorros no ambiente escolar para o mundo todo. ${ }^{14}$

Nesse sentido, o ambiente escolar recebe destaque como o principal ambiente para o desenvolvimento das funções cognitivas de crianças, adolescentes e jovens. A escola é um local em que ocorre o processo sistematizado de ensino-aprendizagem para a formação de um indivíduo, complementando a educação familiar recebida pelo mesmo. ${ }^{13}$

Destarte, outros estudos também realçaram a importância de se ensinar o tema PS para crianças e adolescentes ${ }^{9,15}$, posto que todo indivíduo tem um papel e uma responsabilidade perante a sociedade, sendo um agente transformador dos diferentes cenários fora do ambiente escolar. ${ }^{16}$ Assim, ensinar PS para crianças e adolescentes tem como objetivo formar adultos mais 
preparados, conscientes e seguros, uma vez que é durante a infância e adolescência que ocorre o processo de formação de ideias, sentimentos, hábitos e traços de sua personalidade que influenciarão diretamente o contexto social em que vivem. ${ }^{15}$ Vale reforçar que situações de urgência e emergência não escolhem a vítima e nem o local que irão acontecer. Sendo assim, todos precisam estar preparados para prestar os PS às vítimas.

Um estudo exploratório, de campo, desenvolvido com o objetivo de avaliar o conhecimento dos estudantes sobre noções básicas de PS ratifica que os acidentes por causas externas ocorrem a todo momento, de modo inesperado e não intencional, o que reforça a ideia de que é indispensável que seja realizada uma capacitação da população como um todo quanto às noções básicas de PS. Uma sociedade bem orientada e treinada está apta a agir em situações de urgência e emergência para salvar vidas e prevenir sequelas. ${ }^{13}$

Um estudo destaca a necessidade da inclusão da disciplina de PS no ensino básico, quando o indivíduo adulto é capacitando para atuar em situações onde há o risco iminente de sequelas e danos irreversíveis. ${ }^{12}$ Nessa perspectiva, o governo criou o Programa Saúde na Escola (PSE) que visa à integração e articulação permanente da educação e da saúde, proporcionando melhoria da qualidade de vida dos educandos, por meio de ações de promoção da saúde, de prevenção de doenças e agravos e de atenção à saúde, com vistas ao enfrentamento das vulnerabilidades. ${ }^{17}$ O PSE tornou possível integrar a educação em saúde à grade curricular da educação básica brasileira. Destarte, o enfermeiro como parte integrante da equipe de saúde passa a ser um agente propagador de conhecimentos nas escolas, fazendo a parceria entre o setor de Educação e o setor de Saúde e colaborando, assim, para a formação deste público, a partir do ensino de PS nestes locais. Portanto, o enfermeiro pode ser um facilitador e propulsor de conhecimentos na vigência do PSE.

De maneira geral, a maioria dos estudos faz uma abordagem acerca do conhecimento de estudantes sobre os temas de PS. Entretanto, encontraram-se alguns estudos que abordaram a 
temática específica de PCR e RCP.9,12,15,18-23 Quanto ao conhecimento prévio sobre PCR, observou-se que a maioria dos participantes não sabia como identificá-la e nem como proceder após a sua identificação. Sabe-se que as doenças cardiovasculares representam a principal causa de mortalidade no Brasil e no mundo, assim como, a principal causa de incapacidades. Estimase que aproximadamente 330.000 PCR's ocorrem anualmente em um âmbito extra-hospitalar como residências, shopping centers, aeroportos, estádios, academias e outros espaços nos Estados Unidos da América (EUA), associada a desfecho trágico. Assim como nos EUA, a PCR lidera as causas de óbito na Europa e afeta entre 350.000 e 700.000 indivíduos por ano, representando cerca de $30 \%$ da população. ${ }^{18}$ Isto posto, é importante que todos estejam preparados para reconhecer e assistir as vítimas nesta situação, prestando o SBV.

Um trabalho realizado em municípios do Meio Oeste de Santa Catarina ressaltou que a RCP pode ser realizada por qualquer pessoa e quando bem-executada, pode resultar na manutenção da circulação para os órgãos vitais até a chegada de um atendimento especializado. Ademais, o treinamento de leigos constitui uma estratégia que pode salvar muitas vidas nessas situações. ${ }^{19}$ Outras pesquisas também comprovam a pesquisa, como o desenvolvido em uma instituição privada de ensino na cidade de Londrina/Paraná, em que a rápida identificação da vítima pelo leigo que assiste uma PCR e chama por socorro especializado e, inicia imediatamente as manobras de RCP, favorece um bom prognóstico e previne a deterioração miocárdica e possíveis sequelas neurológicas. ${ }^{15}$ Tal premissa também foi destacada em outra pesquisa semelhante. ${ }^{19}$

Outra pesquisa desenvolvida em duas escolas na cidade de Maceió/Alagoas reforçou a necessidade de capacitar estudantes para prestar o SBV com o ensino de RCP, a partir da inclusão desta temática no currículo escolar. Destarte, quanto mais cedo se ensina e treina indivíduos leigos em SBV, maior será a chance de ter, no futuro, uma ampla base de adultos que contribuam para a diminuição de sequelas e óbitos decorrentes das causas externas. E ainda, 
Intervenção educativa em primeiros socorros para escolares da educação básica | 12

reitera que crianças e adolescentes têm predisposição para comentar e discutir o conteúdo aprendido e treinado com pais, irmãos, amigos e outros membros da família e comunidade, o que ampliaria a disseminação deste conhecimento. ${ }^{9}$

Diante do exposto, vale ressaltar que a educação permanente é um processo de construção que requer tempo, dedicação e continuidade, tornando-se necessário que seja realizada com uma maior periodicidade para que dúvidas e possíveis falhas possam ser sanadas. Como demonstra uma investigação realizada na Ghent University Hospital com estudantes do terceiro ano de medicina, em que os resultados para o desempenho dos estudantes durante a execução das manobras de RCP foram inferiores e deficitárias à metodologia proposta utilizada, sendo necessário um treinamento adicional que, posteriormente, foi altamente eficaz para a melhoria dessas habilidades de compressão e ventilação. ${ }^{20}$

Neste ínterim, a adoção de periódicas atualizações podem propiciar e beneficiar a apreensão dos conhecimentos e habilidades em SBV por parte dos indivíduos a serem capacitados. E isso destaca a necessidade de se promover uma avaliação e reciclagem mais frequentes como traz o guideline da ERC, que mostra que as habilidades de RCP decaem dentro de três a seis meses após o treinamento inicial. ${ }^{21}$

Evidenciou-se em outro estudo com enfermeiros que atuam nas unidades clínicas, cirúrgicas e intensivas de pacientes adultos, a necessidade de se instituir treinamentos frequentes e sistemáticos por meio de educação permanente, de modo a preservar e manter um bom desempenho do indivíduo que vai prestar assistência à vítima em PCR. ${ }^{22} \mathrm{O}$ que torna importante e fundamental a educação permanente dos indivíduos que recebem capacitação em PS, como é o caso do SBV que se atualiza a cada cinco anos. ${ }^{23}$ Do mesmo modo, reforçou-se em outro estudo a contribuição da qualificação da população leiga para a redução direta e indireta da mortalidade, assim como, da gravidade de sequelas decorrentes de agravos súbitos, ocorridos em ambientes extra-hospitalares..$^{24}$ 


\section{Considerações finais}

O presente estudo demonstrou que a intervenção educativa em primeiros socorros para estudantes de uma escola pública foi efetiva para a maioria dos assuntos abordados, porém, alguns tópicos, ainda precisam ser mais trabalhados. Diante do exposto, destaca-se a necessidade de implementar disciplinas que se apliquem a estes conteúdos no currículo dos mesmos para que eles possam aprimorar o conhecimento na área supracitada.

Este estudo teve como limitações algumas dificuldades enfrentadas pelos pesquisadores em realizar a intervenção educativa em curto espaço de tempo, inviabilizando, assim, o treinamento prático de todos os temas abordados e o fato de ter sido desenvolvido em apenas uma escola. Percebeu-se a insuficiência de um período maior de tempo para trabalhar estes tópicos e para discutir os mesmos com os estudantes, para que o conhecimento fosse melhor consolidado. Tal dificuldade reforça a conveniência de inclusão da temática nas escolas.

Destarte, sugere-se a revisão dos modelos curriculares das escolas brasileiras acerca do ensino de PS para crianças e adolescentes em idade escolar, com a inclusão desta temática em uma disciplina pertencente à grade curricular, assim como, a realização de outras pesquisas em diferentes instituições de ensino, visando disseminar este conhecimento a outros estudantes.

A pesquisa contribuiu para subsidiar a inovação de intervenções educativas e reflexões sobre a importância de promover uma educação permanente sobre a temática de PS para a população leiga, especialmente em idade escolar, visto que é na escola em que há uma troca mútua de saberes e o aprendizado de novos conteúdos, gerando assim um conhecimento consolidado e a formação de indivíduos capazes de transformar o contexto social em que se encontram inseridos.

Logo, é indispensável que o acesso a estes conhecimentos seja democratizado e disseminado para toda a sociedade, permitindo aos usuários cuidar melhor de sua saúde e tornarem-se menos vulneráveis. Contribuindo assim de forma direta na redução do número de 
Intervenção educativa em primeiros socorros para escolares da educação básica | 14

vítimas que sofrem óbitos devido ao desconhecimento, despreparo e a demora em receber o atendimento pré-hospitalar em locais distantes e que não tenham disponíveis o Serviço de Atendimento Móvel de Urgência (SAMU).

\section{Referências}

1. Mena H, Piacsek GVM, Motta MV. Urgência e emergência: os conceitos frente às normas administrativas e legais e suas implicações na clínica médica. Saúde Ética Justiça [Internet]. 2017 [acesso em 2019 fev 26];22(2):81-94. Disponível em: http://www.revistas.usp.br/sej/article/view/144375/147091

2. Tavares LFB, Bezerra IMP, Oliveira FR, Sousa LVA, Raimundo RD, Sousa EC, et al. Conhecimento de estudantes de graduação em ciências da saúde em testes objetivos sobre Suporte Básico de Vida. Rev Bras Crescimento Desenvolv Hum [Internet]. 2015 [acesso em 2019 fev 26];25(3):297-306. Disponível em: http://pepsic.bvsalud.org/pdf/rbcdh/v25n3/pt_08.pdf

3. Ragadali Filho A, Pereira NA, Leal I, Anjos QS, Loose JTT. A importância do treinamento de primeiros socorros no trabalho. Rev Saberes [Internet]. 2015 [acesso em 2019 fev 17];3(2):114-25. Disponível em: https://facsaopaulo.edu.br/wp-content/uploads/sites/16/2018/05/ed3/10.pdf

4. Khatatbeh M. First aid knowledge among university students in Jordan. Int J Prev Med [Internet]. 2016 [acesso em 2019 fev 17];7:24. Disponível em: https://www.ncbi.nlm.nih.gov/pmc/articles/PMC4755219/

5. Silva DP, Nunes JBB, Moreira RTF, Costa LC. Primeiros socorros: objeto de educação em saúde para professores. Rev Enferm UFPE On Line [Internet]. 2018 [acesso em 2019 fev 17];12(5):1444-53. Disponível em: https://periodicos.ufpe.br/revistas/revistaenfermagem/article/viewFile/234592/28912

6. Ferreira MGN, Alves SRP, Souto CGV, Virgínio NA, Silva Júnior JNB, Santos AF. O leigo em primeiros socorros: uma revisão integrativa. Rev Ciênc Saúde Nova Esperança [Internet]. 2017 [acesso em 2019 fev 26];15(3):12-20. Disponível em: http:/www.facene.com.br/wp-content/uploads/2010/11/Artigo-02.pdf

7. LGS Silva, JB Costa, LGS Furtado, JB Tavares, JLD Costa. Primeiros socorros e prevenção de acidentes no ambiente escolar: intervenção em unidade de ensino. Enferm Foco [Internet]. 2017 [acesso em 2019 fev 17];8(3):25-9. Disponível em: http://biblioteca.cofen.gov.br/wp-content/uploads/2018/03/Primeirossocorros-e-preven\%C3\%A7\%C3\%A3o-de-acidentes-no-ambiente-escolar.pdf

8. Bandyopadhyay L, Manjula M, Paul B, Dasgupta A. Effectiveness of first-aid training on school students in Singur Block of Hooghly District, West Bengal. J Family Med Prim Care [Internet]. 2017 [acesso em $2019 \mathrm{fev}$ 17];6(1):39-42. Disponível em: https://www.ncbi.nlm.nih.gov/pmc/articles/PMC5629897/

9. Fernandes JMG, Leite ALS, Auto BSD, Lima JEG, Rivera IR, Mendonça MA. Ensino de suporte básico de vida para alunos de escolas pública e privada do ensino médio. Arq Bras Cardiol [Internet]. 2014 jun 
[acesso em 2019 fev 16];102(6):593-601. Disponível em: http://www.scielo.br/pdf/abc/v102n6/pt_0066-782Xabc-20140071.pdf

10. Tavares A, Pedro N, Urbano J. Ausência de formação em suporte básico de vida pelo cidadão: um problema de saúde pública? Qual a idade certa para iniciar? Rev Port Saúde Pública [Internet]. 2016 [acesso em 2019 fev 26];34(1):101-4. Disponível em: http://www.scielo.mec.pt/scielo.php?script=sci_abstract\&pid=S0870-90252016000100014\&lng=pt\&nrm=iso

11. Firmino MJACS. Testes de hipóteses: uma abordagem não paramétrica [dissertação]. Lisboa: Faculdade de Ciências da Universidade de Lisboa; 2015 [acesso em 2019 fev 26]. Disponível em: https://repositorio.ul.pt/bitstream/10451/18146/1/ulfc113805_tm_Maria_Jos\%25C3\%25A9_Firmino.pdf

12. Matos DON, Souza RS, Alves SM. Inclusão da disciplina de primeiros socorros para alunos do ensino básico. Rev Interdiscip [Internet]. 2016 [acesso em 2019 fev 16];9(3):168-78. Disponível em: https://revistainterdisciplinar.uninovafapi.edu.br/index.php/revinter/article/view/923

13. Albuquerque AM, Gouveia BLA, Lopes CAA, Ferreira JA, Pinto MB, Santos NCCB. Salvando vidas: avaliando o conhecimento de adolescentes de uma escola pública sobre primeiros socorros. Rev Enferm UFPE On Line [Internet]. 2015 [acesso em 2019 fev 16];9(1):32-8. Disponível em: https://periodicos.ufpe.br/revistas/revistaenfermagem/article/viewFile/10303/10969

14. Boaventura AP, Mandl SRM, Moraes ESS, Simões C, Gaspar AR, Vedovato C. Primeiros socorros no ambiente escolar. Relato de experiência na divisão de educação infantil e complementar da Universidade Estadual de Campinas. Rev Saberes Univ [Internet]. 2017 [acesso em 2019 fev 16];2(2):147-58. Disponível em: https://econtents.bc.unicamp.br/inpec/index.php/saberes/article/view/7596

15. Terassi M, Borges AKPG, Garanhani ML, Martins EAP. A percepção de crianças do ensino fundamental sobre parada cardiorrespiratória. Semina Ciênc Biol Saúde [Internet]. 2015 [acesso em $2019 \mathrm{fev}$ 16];36(1 supl):99-108. Disponível em: http://www.uel.br/revistas/uel/index.php/seminabio/article/view/19145

16. Carneiro RP. Reflexões acerca do processo ensino-aprendizagem na perspectiva freireana e biocêntrica. Rev Thema [Internet]. 2012 [acesso em $2019 \mathrm{fev}$ 16];09(02):01-18. Disponível em: http://revistathema.ifsul.edu.br/index.php/thema/article/view/145

17. Ministério da Saúde (BR). Caderno do gestor do PSE. Brasília(DF): Ministério da Saúde; Ministério da Educação; 2015 [acesso em 2019 fev 26]. Disponível em: http://bvsms.saude.gov.br/bvs/publicacoes/caderno_gestor_pse.pdf

18. Canova JCM, Cyrillo RMZ, Hayashida M, Pompeo DA, Ribeiro RCH, Dalri MCB. Parada cardiorrespiratória e ressuscitação cardiopulmonar: vivências da equipe de enfermagem sob o olhar da técnica do incidente crítico. Rev Enferm UFPE On Line [Internet]. 2015 [acesso em 2019 fev 17];9(3):7095103. Disponível em: https://periodicos.ufpe.br/revistas/revistaenfermagem/article/view/10439 
19. Dallacosta FM, Dorini D, Rosa LA. Reanimação cardiopulmonar: experiência no treinamento em escolas. Cataventos [Internet]. 2017 [acesso em 2019 fev 15];9(1):29-39. Disponível em: http://revistaeletronica.unicruz.edu.br/index.php/Cataventos/article/view/5314

20. Mpotos N, Yde L, Calle P, Deschepper E, Valcke M, Peersman W, et al. Retraining basic life support skills using video, voice feedback or both: a randomised controlled trial. Resuscitation [Internet]. 2013 [acesso em 2019 fev 15];84:72-7. Disponível em: https:/www.resuscitationjournal.com/article/S03009572(12)00740-X/pdf

21. Soar J, Monsieurs KG, Ballance JH, Barelli A, Biarent D, Greif R, et al. European Resuscitation Council Guidelines for Resuscitation 2010. Section 9. Principles of education in resuscitation. Resuscitation [Internet]. 2010 [acesso em 2019 fev 15];81(10):1434-44. Disponível em: https://www.resuscitationjournal.com/article/S0300-9572(10)00440-5/fulltext

22. Bertoglio VM, Azzolin K, Souza EN, Rabelo ER. Tempo decorrido do treinamento em parada cardiorrespiratória e o impacto no conhecimento teórico de enfermeiros. Rev Gaúch Enferm [Internet]. 2008 [acesso em 2019 fev 15];29(3):454-60. Disponível em: https://lume.ufrgs.br/bitstream/handle/10183/23606/000670698.pdf?sequence=1

23. Freitas JR, Péllenz DC. Parada cardiorrespiratória e atuação do profissional enfermeiro. Rev Saberes UNIJIPA [Internet]. 2018 [acesso em 2019 fev 26];8(1):74-84. Disponível em: https://unijipa.edu.br/wpcontent/uploads/Revista\%20Saberes/ed8/6.pdf

24. Galindo Neto NM, Sá GGM, Vasconcelos EMR, Silva TM, Santos AMR, Carvalho KM. Intervenções de educação em saúde sobre primeiros socorros para leigos no Brasil: revisão integrativa. Cienc Cuid Saúde [Internet]. 2017 [acesso em $2019 \mathrm{fev}$ 15];16(4):1-9. Disponível em: http://periodicos.uem.br/ojs/index.php/CiencCuidSaude/article/view/38305

\section{Autor correspondente}

Monalise Mara Rocha Santana.

E-mail: monalisemrsantana@gmail.com

Endereço: Travessa Demerval Olivier de Paula, n 25/ Apto. 303 - Centro - Muriaé/Minas Gerais - Brasil.

CEP: 36880-033

\section{Contribuições de Autoria}

\section{1 - Monalise Mara Rocha Santana}

Contribuiu substancialmente nas etapas de concepção e planejamento do projeto de pesquisa, obtenção, análise e interpretação dos dados, bem como da redação e revisão crítica do manuscrito. 
17 | Santana MMR, Toledo LV, Moreira TR, Alves KR, Ribeiro L, Sá Diaz FBB

\section{2 - Luana Vieira Toledo}

Contribuiu substancialmente na etapa de revisão crítica do manuscrito.

\section{3 - Tiago Ricardo Moreira}

Contribuiu substancialmente nas etapas de análise e interpretação dos dados, bem como da revisão crítica do manuscrito.

\section{4 - Katiusse Rezende Alves}

Contribuiu substancialmente na etapa de revisão crítica do manuscrito.

\section{5 - Luciane Ribeiro}

Contribuiu substancialmente na etapa de revisão crítica do manuscrito.

\section{6 - Flávia Batista Barbosa de Sá Diaz}

Contribuiu substancialmente nas etapas de concepção e planejamento do projeto de pesquisa, obtenção, análise e interpretação dos dados, bem como da redação e revisão crítica do manuscrito.

\section{Como citar este artigo}

Santana MMR, Toledo LV, Moreira TR, Alves KR, Ribeiro L, Sá Diaz FBB. Intervenção educativa em primeiros socorros para escolares da educação básica. Rev. Enferm. UFSM. 2020 [Acesso em: Anos Mês Dia]; vol.10 e70: 1-17. DOI: https://doi.org/10.5902/2179769236507 